\title{
O uso de tecnologia e o acesso à água na zona rural de um município do nordeste do Estado do Pará
}

O conceito de zona rural é comumente relacionado com o de zona urbana, uma vez que é classificada como o território fora dos limites do processo de urbanização. Por isso, a zona urbana sempre foi privilegiada no que concerne à implantação de sistemas de água encanada e potável, em detrimento à zona rural. Diante disso esta pesquisa objetivou demonstrar que o uso de tecnologias no meio rural, sejam elas inovadoras ou não, facilita o acesso à água. A pesquisa foi realizada no município de Nova Timboteua, no nordeste do estado do Pará. Quanto ao método, utilizou-se o dedutivo, pois partiu-se de duas premissas positivas para uma conclusão verdadeira. A pesquisa apresenta abordagem qualitativa e quantitativa, de natureza aplicada, com procedimento exploratório. Em relação ao acesso e à captação da água na comunidade rural Sapucaia, os dados obtidos e analisados indicaram que $29(96,6 \%)$ das 30 famílias que são totalmente dependentes das nascentes para realizar qualquer tipo atividade que necessite do recurso hídrico, não dispõe de nenhum mecanismo tecnológico que auxilie na captação e/ou facilite o acesso à água. Com a verificação dos dados, o Sítio Jonas é a única propriedade na comunidade a utilizar um motobomba de $40 \mathrm{HP}$ de potência interligado a um sistema de encanação adaptado, que transporta a água do igarapé para reservatórios da residência e para irrigação de uma plantação de hortaliças. Nesse sentido, por mais que haja uma considerável facilidade de acesso à água na propriedade supramencionada, ainda existem 29 famílias que captam o recurso de forma primitiva e lenta, fato que ressalta a importância de um sistema de água encanada.

Palavras-chave: Saneamento básico; Cultivo agrícola; Irrigação; Captação.

\section{Use of technology and water access in a rural area of northeast of the State of Pará}

The rural area is related to the urban area concept since it is classified as the territory outside the limits of the urbanization process. Therefore, the urban area has always been privileged by the implementation of piped and potable water systems, at a disadvantage to the rural area. In addition, this research aimed to demonstrate that the use of technologies in rural areas, whether innovative or not, facilitates access to water. The present study was conducted in the Nova Timboteua municipality, northeast of the state of Pará. The deductive method was used based on two positive premises for a true conclusion. A qualitative and quantitative approach was showed of applied nature, with the exploratory procedure. The data obtained and analyzed related to the water access and harvesting in the Sapucaia rural community indicated that 29 (96.6\%) of 30 families that are dependent on the sources to perform any type of activity that requires water resources. Water harvesting does not have any technological mechanism that assists and/or facilitates access to water. Jonas Sítio is the only property in the community to use a $40 \mathrm{HP}$ power pump interconnected with an adapted plumbing system according to the data verification. This system transports the water from the igarapé into a residential reservoir and a plantation irrigation system of vegetable plantations. Thus, there are still 29 families that tap the resource in a primitive and slow way, although there is considerable ease of access to water on the property. In addition, this situation emphasises the importance of a piped water system.

Keywords: Basic sanitation; Agricultural cultivation; Irrigation; Water harvesting.

Topic: Extensão e Desenvolvimento Rural

Reviewed anonymously in the process of blind peer.
Received: 10/11/2020

Approved: 15/02/2021
Brendo Luiz Araújo Alves (iD

Universidade do Estado do Pará, Brasil

http://lattes.cnpq.br/9762723896318900

http://orcid.org/0000-0003-3306-0766

brendo luiz96@hotmail.com

Vitor Glins da Silva Nascimento (iD

Universidade do Estado do Pará, Brasil

http://lattes.cnpq.br/4410262332942873

http://orcid.org/0000-0002-0814-6122

vitor.glinss@gmail.com

Antônio Pereira Júnior

Universidade do Estado do Pará, Brasil

http://lattes.cnpq.br/3239362677711162

http://orcid.org/0000-0001-6241-985X

antonio.junior@uepa.br

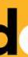

DOI: 10.6008/CBPC2237-9290.2021.001.0002
Francimary da Silva Carneiro (ic)

Universidade Federal Rural da Amazônia, Brasil

http://lattes.cnpq.br/8657235544233319

http://orcid.org/0000-0002-1693-8779

francimarycarneiro@gmail.com

\section{Referencing this:}

ALVES, B. L. A.; NASCIMENTO, V. G. S.; PEREIRA JÚNIOR, A.; CARNEIRO, F. S.. O uso de tecnologia e o acesso à água na zona rural de um município do nordeste do Estado do Pará. Natural Resources, v.11 n.1, p.12-20, 2021. DOI: http://doi.org/10.6008/CBPC2237 9290.2021.001.0002 


\section{INTRODUÇÃO}

O conceito de zona rural é comumente relacionado com o de zona urbana, uma vez que é classificada como o território fora dos limites do processo de urbanização (CLASEN et al., 2014). Assim, a zona rural é uma categoria tradicionalmente localizada, surgida a partir dos diversos processos da industrialização e da urbanização e que constituem progressivamente os campos, em um sistema econômico e político unificados (RODRIGUES, 2015).

Outrossim, a zona urbana das cidades sempre foi privilegiada no que concerne à implantação de sistemas de água encanada e potável, em detrimento à zona rural. Tal fato é justificado pelo grande contingente populacional existente em regiões majoritariamente urbanizadas, fato que retém a maioria dos investimentos em saneamento; o que torna grande parte das comunidades rurais dependentes quase que exclusivamente das nascentes hídricas para sobreviver e desenvolver qualquer tipo de atividade econômica inerente ao cultivo agrícola (PINTO et al., 2015).

Nesse cenário, de acordo com o Instituto Brasileiro de Geografia e Estatística - IBGE, no ano de 2015, a população brasileira que residia em regiões do país consideradas zonas rurais, era aproximadamente de 31 milhões de pessoas (15,28\%). Dessa parcela, apenas 6 milhões e 600 mil (22\%) do total detinham de serviços de saneamento básico, bem como acesso à água potável provinda de sistema de abastecimento. Além disso, estima-se que 24 milhões (12\%) de brasileiros ainda vivam em estado de calamidade no que diz respeito às condições sanitárias básicas, sobretudo, ao consumo de água potável (IBGE, 2015).

Para evitar danos à saúde e à produção familiar devido a esses fatos, a maciça maioria da população rural busca "refúgio" nas nascentes hídricas para atender parte das demandas vitais, tais como o uso doméstico, a dessedentação e a agricultura familiar (ROCKSTROM et al., 2009). Com isso, a água advinda de nascentes é, literalmente, fonte de vida e sustento para essa população, haja vista que esse bem natural também é utilizado na criação de animais e empregado no cultivo de pequenas plantações desenvolvidas pelas comunidades (BISOGNIN et al., 2017).

Assim, a água é um dos recursos naturais mais significativos do planeta e, também, é caracterizada como um recurso finito (SANTOS et al., 2013). Ademais, o aumento exacerbado e desenfreado da população, e entre outros fatores interligados com esse aumento, ocasionam a degradação dos recursos hídricos em função dos usos múltiplos e regularmente sem controle, como o lazer, a pecuária e a agricultura (PIRATOBA et al., 2017; ZHANG et al., 2010).

Diante disso, embasado na Lei n. 11.445, de 05 de janeiro de 2007, que dispõe sobre as diretrizes nacionais e política federal para o saneamento básico no Brasil, o mesmo é conceituado como a disponibilidade e garantia ao abastecimento de água potável, esgotamento sanitário, limpeza urbana/rural e a realização adequada da destinação e manejo de resíduos sólidos, de forma a beneficiar a saúde pública e proteger o ambiente (LEONETI et al., 2012).

Ademais, na zona rural, os entraves de políticas públicas, dependências tecnológicas e gerenciais tornam trabalhosa a proliferação dos benefícios referentes ao devido e necessário saneamento rural (BUCCI 
et al., 2014). Por isso, predomina o uso e consumo de água de forma inadequada, sem conhecimento prévio dos parâmetros que garantem a potabilidade da mesma, em especial a concentração de coliformes, sobretudo, os termotolerantes; fator que torna vulnerável a saúde e a qualidade de vida da população rural (HOLGADO-SILVA et al., 2014).

Dessa forma, conhecer as formas de acesso e os diferentes usos da água de uma determinada comunidade rural, que não dispõe de um sistema de água potável encanada, muito menos de um adequado saneamento rural; é muito importante frente a realidade de vulnerabilidade socioambiental ocasionada por esses fatores. Diante disso, esta pesquisa objetivou demonstrar que o uso de tecnologias no meio rural, sejam elas inovadoras ou não, facilita o acesso à água.

\section{METODOLOGIA}

\section{Fisiografia do município}

A pesquisa foi realizada no município de Nova Timboteua (Figura 1), no nordeste do estado do Pará com latitude de 02ㅇ 02' 47" S e longitude de 47ㅇ 33' 02" W. População estimada em 14.942, apresenta área total de $489.853 \mathrm{~km}^{2}$ e com densidade demográfica de 27,91 habitantes por km² (IBGE, 2017).

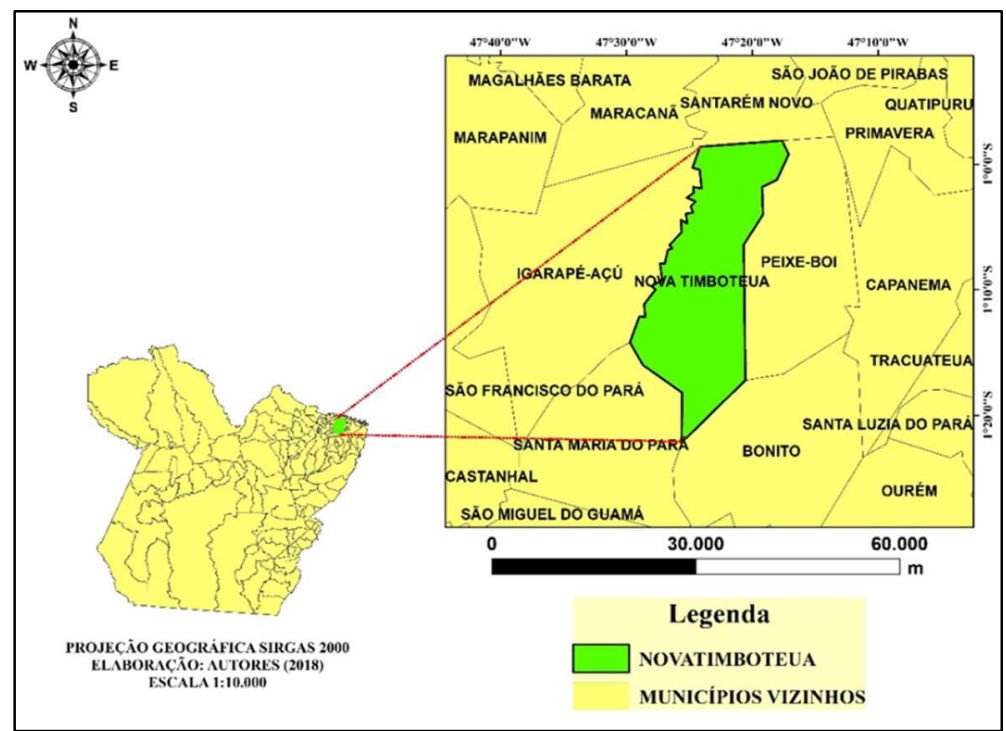

Figura 1: Mapa político e geográfico do município de Nova Timboteua - PA.

Em relação ao solo, há predominância do latossolo amarelo e do concessionário laterítico que são caracterizados como ácidos e porosos; quanto à vegetação, prevalece a floresta secundária, em razão do desmatamento que ocorreu na década de 1990 com a finalidade de desenvolver economicamente a região (RODRIGUES et al., 2009).

\section{Método}

Quanto ao método aplicado, utilizou-se o dedutivo, pois partiu-se de duas premissas positivas para uma conclusão verdadeira: (1) a zona rural brasileira apresenta um elevado déficit no que diz respeito ao saneamento básico, (2) tal deficiência compromete diretamente a qualidade da água usada e consumida pela 
população. Logo, essa problemática prejudica de forma proeminente a qualidade de vida das comunidades rurais através da poluição e/ou contaminação dos corpos hídricos, bem como pelo dificultoso acesso à água (BORGES et al., 2014).

A pesquisa apresenta abordagem qualitativa e quantitativa, de natureza aplicada, com procedimento exploratório (SAKAMOTO et al., 2014), pois na comunidade Sapucaia, esse tipo de pesquisa ainda não ocorreu. Nesse sentido, o método foi associado ao levantamento de dados documentais com o recorte temporal compreendido entre os anos de 2009 e 2018, em razão dos trabalhos científicos com grande significância sobre a temática dos recursos hídricos qualidade da água e a zona rural se concentrarem nesse período, além de apresentarem atualidade de dados no intervalo selecionado. Para melhor compreender o desenvolvimento da pesquisa, a mesma foi dividida em duas etapas (Figura 2).

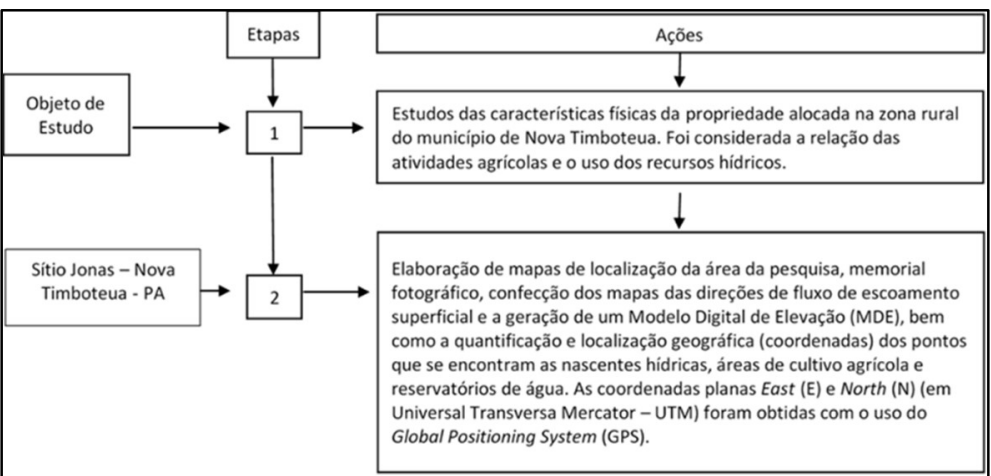

Figura 2: Fluxograma das etapas desenvolvidas na execução da pesquisa. Sítio Jonas. Nova Timboteua - PA.

A área da pesquisa (Figura 3) foi escolhida em razão da ausência de um sistema de abastecimento de água na comunidade, além da mesma não possuir nenhuma forma de saneamento básico.

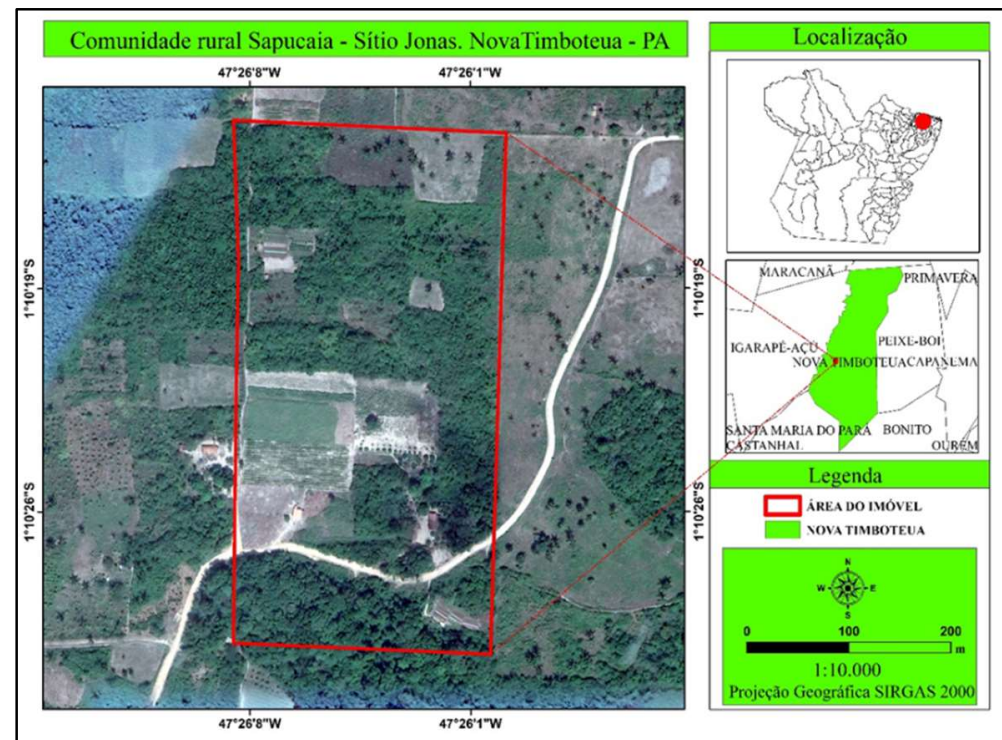

Figura 3: Localização da área da pesquisa - Sítio Jonas. Nova Timboteua - PA

Os residentes não dispõem de água potável encanada, por isso, o abastecimento é efetuado de forma primitiva (baldes, potes, etc.), ou seja, caminham até a fonte, coletam a água, colocam por sobre a cabeça e retornam e, em algumas exceções, realizam coleta com o auxílio de motobombas, que facilitam o trabalho e captam água de nascentes existentes nos limites da propriedade rural (Sítio Jonas). 


\section{RESULTADOS E DISCUSSÃO}

\section{Formas de acesso e captação da água}

Em relação ao acesso e à captação da água na comunidade rural, 29 (96,6\%) das 30 famílias que são totalmente dependentes das nascentes para realizar qualquer tipo atividade que necessite do recurso hídrico como, por exemplo, o consumo humano, não dispõe de nenhum mecanismo tecnológico que auxilie na captação e/ou ao acesso à água. Por esse motivo, os moradores utilizam recipientes de volume conhecido (baldes e potes de cerâmica) para coletar e transportar água para reservatórios e residências (Figura 4).

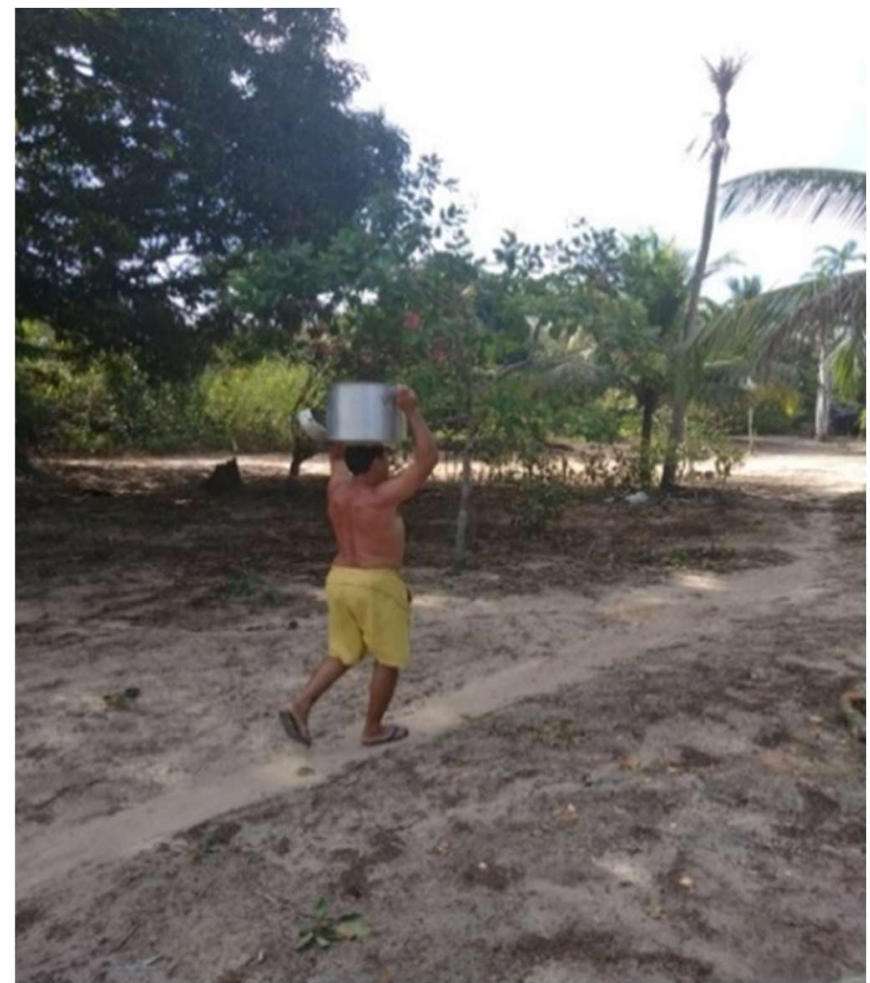

Figura 4: Morador transportando água para residência. Comunidade Sapucaia. Nova Timboteua - PA.

A situação revela a dimensão do déficit em que a zona rural se encontra no que tange o saneamento básico, sobretudo, o acesso à água potável. Dados contidos na Pesquisa Nacional por Amostra de Domicílios (PNAD) realizada em 2015 pelo IBGE, concluíram que das aproximadamente 31 milhões de pessoas residentes em zonas rurais, cerca de 24 milhões não possuíam acesso a água potável encanada. Na pesquisa realizada na zona rural do município de Nova Timboteua, os dados obtidos refletiram o cenário da calamidade em que se encontra a zona rural do Brasil no que diz respeito ao saneamento básico, pois maciça maioria das famílias não dispõe de água advinda de um sistema de abastecimento ou soluções alternativas (Ex.: poços tubulares).

Em contraste as 29 famílias com acesso à água de forma primitiva, o Sítio Jonas é o único na comunidade a utilizar um motobomba de $40 \mathrm{HP}$ de potência (Figura 5a) interligado a um sistema de encanação adaptado, que transporta a água do igarapé para reservatórios da residência (Figura 5b) e para irrigação da horticultura (Figura 5c). 


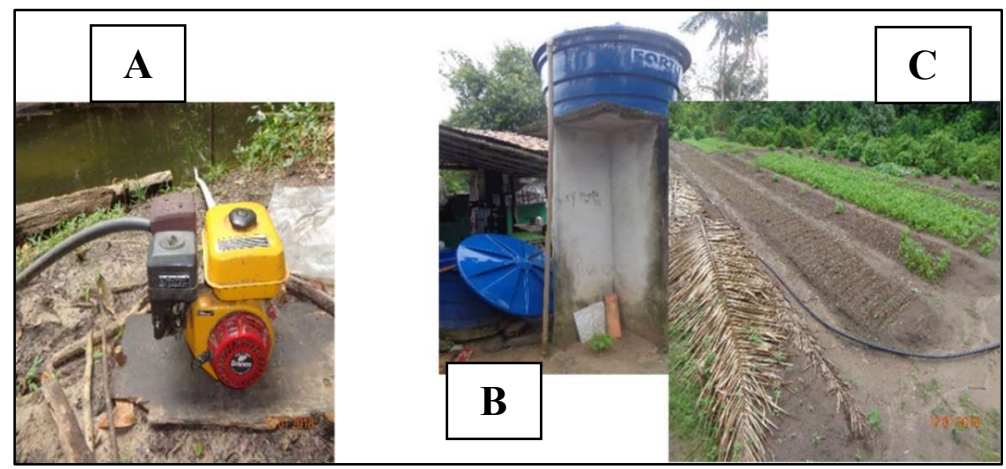

Figura 5: a) motobomba de 40 HP utilizado para captação de água; b) reservatórios da residência; c) encanações para irrigação de horticultura. Sítio Jonas. Nova Timboteua - PA.

Em estudo realizado por Rockstrom et al. (2009) em Londres, indicou que o avanço da tecnologia e o uso de ferramentas atreladas (Ex.: motobomba), minimizou em grande escala as insuficiências e inseguranças da humanidade, em especial, o acesso facilitado a água no campo. No Sítio Jonas, o emprego da tecnologia de motobomba, proporciona aos moradores uma significativa comodidade no processo de captação da água, considerando que em aproximadamente 20 minutos são preenchidos 1800 Litros correspondentes aos dois reservatórios existentes na residência; sendo também indispensável para o cultivo de horticultura da propriedade.

\section{As influências sobre a qualidade da água das nascentes}

\section{Quanto ao relevo}

Em relação ao relevo da propriedade rural em que as nascentes se encontram, os dados obtidos indicaram que, para o sítio Jonas, o intervalo de maior valor $(51,76 \mathrm{~m})$ concentra-se na extremidade norte, enquanto que o intervalo de menor valor (34,07 m), está localizado no limite sul da propriedade (Figura 6a), eles também indicaram que a área onde as nascentes se alocam (extremidade sul a direita do terreno), apresentam as menores elevações, bem como o menor grau de declividade (Figura 6b).
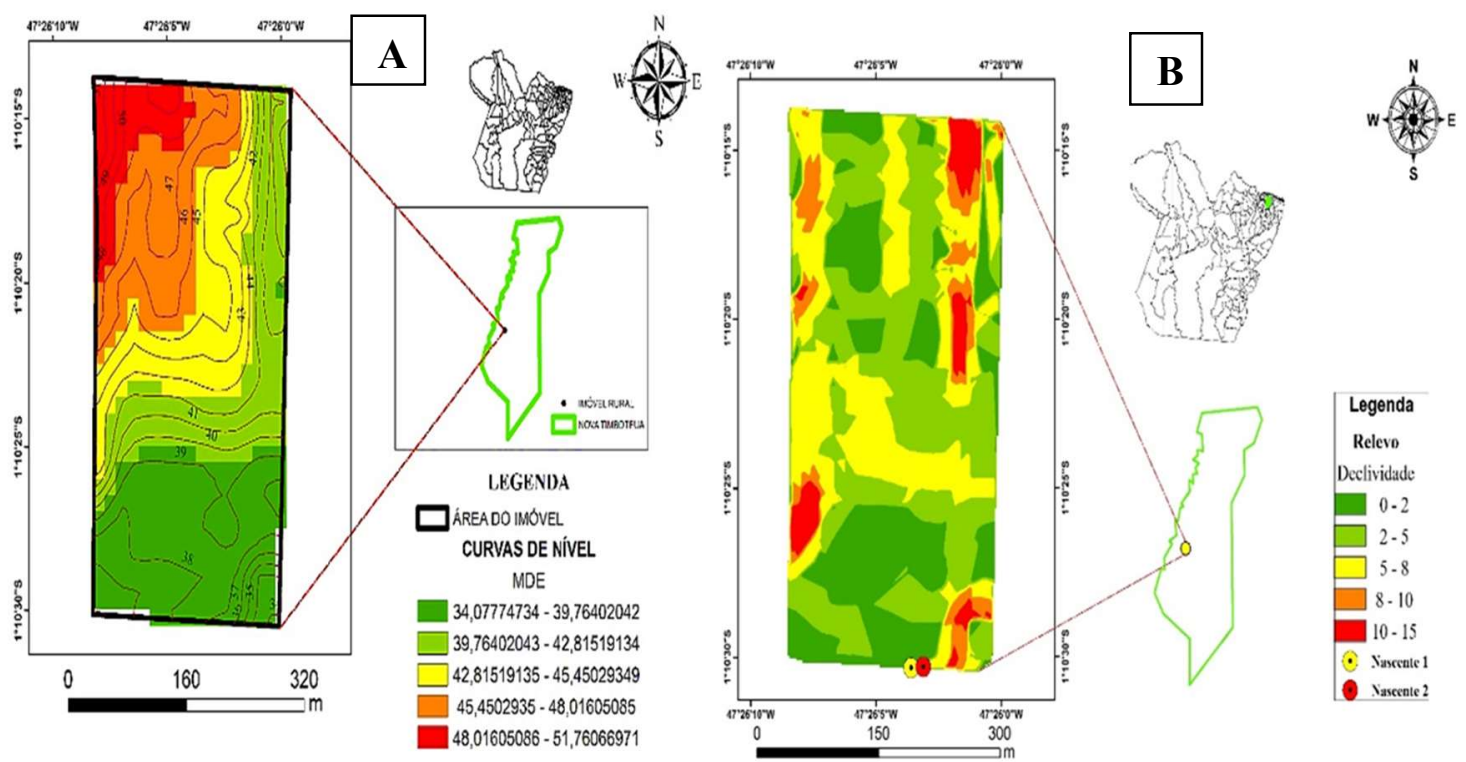

Figura 6: a) Modelo Digital de Elevação - MDE do terreno; b) mapa de declividade do terreno. Sítio Jonas. Nova Timboteua - PA. 
Consoante ao exposto, Santos et al. (2013), com a pesquisa realizada em Ilha Solteira - SP, constatou que a ausência de uma correta utilização de técnicas de manejo do solo, sobretudo, em Áreas de Preservação Permanente (APP), como em caso de nascentes, pode acarretar processos erosivos e o assoreamento de corpos hídricos, principalmente em terrenos que apresentam irregularidades no relevo. Nesse cenário, a característica da elevação da propriedade rural analisada é favorável a ocorrência de erosões e assoreamentos, haja vista que as elevações variam abruptamente de uma extremidade a outra do terreno, fator que pode comprometer a qualidade da água consumida pela comunidade, devido à presença de substâncias no solo com potencial de contaminação, principalmente defensivos agrícolas.

\section{Quanto ao uso e ocupação do solo}

Os dados obtidos mostraram que as 30 (100\%) famílias utilizam o solo para cultivos diversos a nível da agricultura familiar, em que praticam fruticultura (Ex.: maracujá - Passiflora spp.); mandiocultura (Manihot esculenta Crantz), horticultura (Ex.: cheiro verde - Petroselinum crispum) e, em menor escala, a piscicultura (Ex.: tambaqui - Colossoma macropomum Cuvier). No sítio Jonas (Figura 7), há prática intensiva da horticultura, que é desenvolvida durante todo ano, mas, durante o período seco os cultivos são implantados, como forma de estratégia, nas proximidades das nascentes, o que facilita o acesso à água para irrigação.

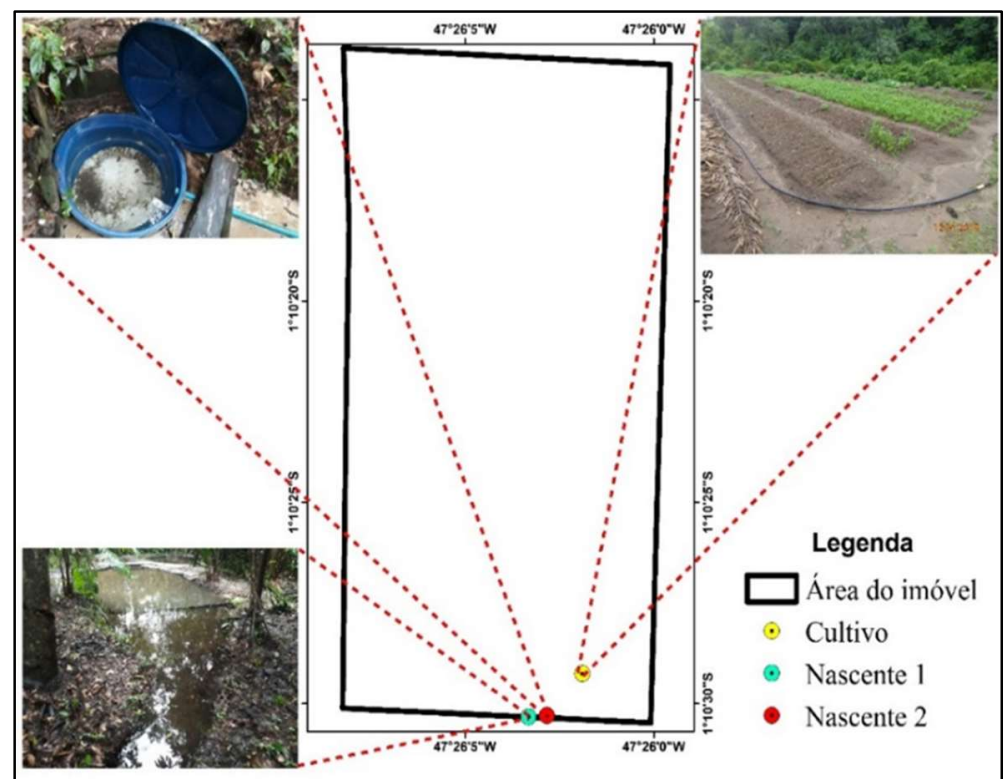

Figura 7: Cultivo de horticultura as proximidades das nascentes. Sítio Jonas - Nova Timboteua - PA.

A análise dos dados também evidenciou que a distância entre o igarapé e a horticultura equivale a 55 metros e, em relação a nascente, dista 40 metros. Por isso, o perímetro existente entre a nascente e a área cultivada infringe a Lei n. 12.651:2012 que institui o Novo Código Florestal, no artigo 4o, inciso IV: delimita como Área de Proteção Permanente (APP), um raio de no mínimo 50 metros no entorno de nascentes e olhos d'água. Na área da pesquisa realizada em Nova Timboteua, a nascente encontra-se parcialmente protegida (Figura 8a), com um reservatório plástico de PVC, com tampa, colocado pela comunidade (Figura 8b). 


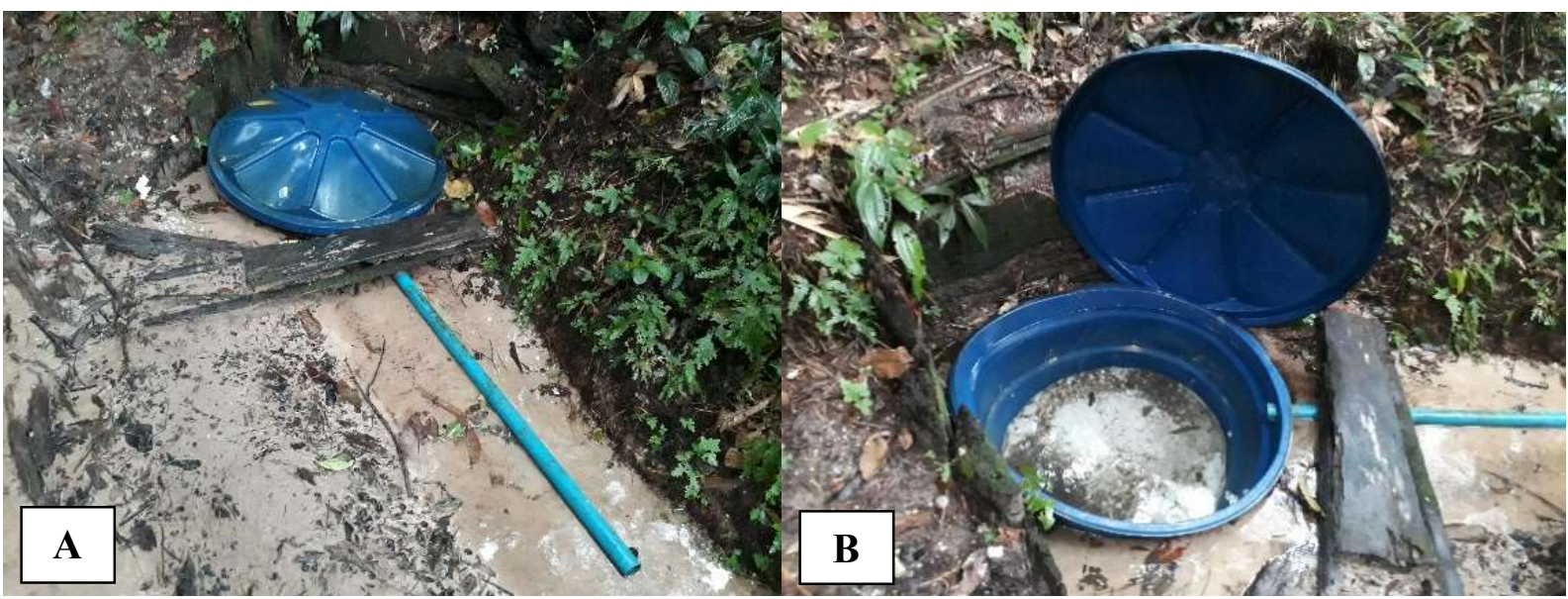

Figura 8: a) adaptação de uma caixa d'água como ferramenta de proteção de nascentes; b) nascente parcialmente protegida. Sítio Jonas. Nova Timboteua - PA.

No município de Juiz de Fora - MG, uma pesquisa realizada por Bucci et al. (2014) indicou que os mananciais e cursos d'água do Brasil apresentaram crescente poluição e/ou contaminação no que diz respeito à qualidade das águas, em decorrência do incorreto lançamento de efluentes, sejam eles domésticos ou industriais, bem como da utilização de agroquímicos em áreas de cultivo, e, sobretudo, do uso e ocupação do solo de maneira indevida e exacerbada. Em Nova Timboteua, pode-se perceber que, na ausência de um monitoramento e controle do uso do solo, principalmente por atividades agrícolas, nas proximidades das nascentes do Sítio Jonas, o risco de a qualidade das águas ser comprometida é significativamente alto, pois há existência do cultivo de horticultura.

\section{CONCLUSÕES}

$\mathrm{Na}$ comunidade rural Sapucaia foi possível perceber que as nascentes desempenham papel social e econômico insubstituível na vida de cada morador, sendo primordial tanto para o consumo quanto para o desenvolvimento de atividades agrícolas. Além do mais, a água proveniente delas também é a única fonte de recurso hídrico que a comunidade possui, por isso ressalta-se a magnitude da importância exercida por elas a cada produtor.

Em relação ao acesso à água, o uso de um motobomba facilitou a captação do recurso no Sítio Jonas, considerando o tempo e esforço que é necessário no translado do recurso para as residências. Com o auxílio da tecnologia, em cerca de 20 minutos são preenchidos reservatórios na residência que estão aproximadamente 150 metros distantes das nascentes, que totalizam um volume de 1800 Litros. Nesse sentido, por mais que haja uma considerável facilidade de acesso à água na propriedade supramencionada, ainda existem 29 famílias que captam o recurso de forma primitiva e lenta, fato que ressalta a importância de um sistema de água encanada.

Por esses motivos, ao conhecer a realidade da comunidade rural estudada, recomenda-se que o poder público atue de forma efetiva, proporcione ao cidadão do meio rurais condições de garantia à qualidade de vida, desenvolvimento social e econômico, através do uso sustentável dos recursos naturais, principalmente os hídricos. Além disso, empregar tecnologias que proporcionem a melhoria da qualidade de vida tanto nos contextos social e ambiental quanto no econômico, tendo em vista que as atividades do campo 
necessitam primordialmente de água, sobretudo no período seco.

\section{REFERÊNCIAS}

BISOGNIN, R. P.; WEBER, F. H.; SILVA, B. R.; WOHLENBERG, P.; VIEIRA, L. F.; BOHRER, R. E. G.. Análise e divulgação da qualidade da água de nascentes, afluentes e ponto de captação do Arroio Lajeado Erval Novo no município de Três Passos/RS. Revista Gestão \& Sustentabilidade Ambiental, Florianópolis, v.6, n.2, p.44-55, 2017. DOI: http://dx.doi.org/10.19177/rgsa.v6e2201744-55

BORGES, N. R. M. B.; PEREIRA, V. T.. Manual de metodologia científica do ILES. Itumbiara: ULBRA, 2014.

BRASIL. Congresso. Senado. Constituição. Lei n. 12.651, de 25 de maio de 2012. Dispõe sobre a proteção da vegetação nativa; altera as leis nos 6.938, de 31 de agosto de 1981, 9.393, de 19 de dezembro de 1996, e 11.428, de 22 de dezembro de 2006; revoga as leis nos 4.771, de 15 de setembro de 1965, e 7.754, de 14 de abril de 1989, e a medida provisória no 2.166-67, de 24 de agosto de 2001; e dá outras providências. Brasília: DOU, 2012.

BUCCI, M. H. S.; OLIVEIRA, L. F. C.. Índices de qualidade da água e de estado trófico na represa Dr. João Penido (Juiz de Fora, MG). Revista Ambiente e Água, Taubaté, v.9, n.1, 2014. DOI: https://doi.org/10.4136/ambi-agua.1290

CLASEN, T.; BOISSON, S.; ROUTRAY, P.; TORONDEL, B.; BELL, M.; CUMMING, O.; ENSINK, J. H. J.; FREEMAN, M.; JENKINS, M. W.; ODAGIRI, M.; RAY, S.; SINHA, A.; SUAR, M.; SCHMIDT, W.-P.. Effectiveness of rural sanitation programme on diarrhoea, soil-transmitted helminth infection, and child malnutrition in Odisha, India: a cluster-randomised trial. Lancet Glob Health, v.2, n.1, p.645-653, 2014. DOI: https://doi.org/10.1016/S2214-109X(14)70307-9

HOLGADO-SILVA, H. C.; PADUA, J. B.; CAMILO, L. R.; DORNELES, T. M.. A qualidade do saneamento ambiental no assentamento rural Amparo no município de DouradosMS. Sociedade \& Natureza, Uberlândia, v.26, n.3, p.535-545, 2014. DOI: http://dx.doi.org/10.1590/1982-451320140311

IBGE. Instituto Brasileiro de Geografia e Estatística. Pesquisa Nacional por amostra de domicílios. Rio de Janeiro: IBGE, 2015.

IBGE. Instituto Brasileiro de Geografia e Estatística. Panorama do município de Nova Timboteua - Pará. Nova Timboteua: IBGE, 2017.

LEONETI, A. B.; PRADO, E. L.; OLIVEIRA, S. V. W. B.. Saneamento básico no Brasil: considerações sobre investimentos e sustentabilidade para o século XXI. Revista de Administração Pública, v.45, n.2, p.331-348, 2012. DOI: https://doi.org/10.1590/S0034-76122011000200003

PINTO, C. M. A.; ARAÚJO, N. A.; SILVA JÚNIOR, D. Diagnóstico Preliminar do Saneamento Rural na Comunidade de Engenho Velho no Município de João Pessoa/PB. Revista Ambiental, João Pessoa, v.1, n.1, p.26-36, 2015.

PIRATOBA, A. R. A.; RIBEIRO, H. M. C.; MORALERS, G. P.; GONÇALVES, W. G.. Caracterização de parâmetros de qualidade da água na área portuária de Barcarena, PA, Brasil. Revista Ambiente e Água, Taubaté, v.12, n.3, p.435456, 2017. DOI: https://doi.org/10.4136/ambi-agua.1910

ROCKSTROM, J.; STEFFEN, W.; NOONE, K.; PERSSON, A.; CHAPIN III, F. S.; LAMBIN, E. F.; LENTON, T. M.; SCHEFFER, M.; FOLKE, C.; SCHELLNHUBER, H. J.; NYKVIST, B.; WIT, C. A.; HUGHES, T.; VAN DER LEEUW, S.; RODHE, H.; SORLIN, S.; SNYDER, P. K.; COSTANZA, R.; SVEDIN, U.; FALKERNMARK, M.; KARLBERG, L. CORELL, R. W.; FABRY, V. J.; HANSEN, J.; WALKER, B.; LIVERMAN, RICHARDSON, K.; CRUTZEN, P.; FOLEY, J. A.. A safe operating space for humanity. Nature, London, n.461, p.472-475, 2009. DOI:

https://doi.org/10.1038/461472a

RODRIGUES, J. F.. O rural e o urbano no Brasil: uma proposta de metodologia de classificação dos municípios. Revista Análise Social, Lisboa, v.211, n.59, p.430-456, 2015.

RODRIGUES, T. E.; SILVA, J. M. L.; VALENTE, M. A.; SANTOS, E. S.; ROLLIN, P. A. M.. Caracterização e classificação dos solos do município de Peixe-Boi, Estado do Pará. Belém: Embrapa Amazônia Oriental, 2009.

SAKAMOTO, C. K; SILVEIRA, I. O.. Como fazer projetos de iniciação científica. São Paulo: Paulus, 2014.

SANTOS, G. O.; HERNANDEZ, F. B. T.. Uso do solo e monitoramento dos recursos hídricos no córrego do Ipê, llha Solteira, SP. Revista Brasileira de Engenharia Agrícola Ambiental, Campina Grande, v.17, n.1, p.60-68, 2013. DOI: https://doi.org/10.1590/S1415-43662013000100009

ZHANG, Z.; TAO, F.; DU, J.; SHI, P.; YU, D.; MENG, Y.; SUN, Y.. Surface water quality and its control in a river with intensive human impacts: a case study of the Xianqjiang River, China. Jornal of Environmental Management, v.91, n.12, p.24832490, 2010. DOI: http://doi.org/10.1016/j.jenvman.2010.07.002

A CBPC - Companhia Brasileira de Produção Científica (CNPJ: 11.221.422/0001-03) detém os direitos materiais desta publicação. Os direitos referem-se à publicação do trabalho em qualquer parte do mundo, incluindo os direitos às renovações, expansões e disseminações da contribuição, bem como outros direitos subsidiários. Todos os trabalhos publicados eletronicamente poderão posteriormente ser publicados em coletâneas impressas sob coordenação da Sustenere Publishing, da Companhia Brasileira de Produção Científica e seus parceiros autorizados. Os (as) autores (as) preservam os direitos autorais, mas não têm permissão para a publicação da contribuição em outro meio, impresso ou digital, em português ou em tradução. 